\title{
Heartland Virus Neutralizing Antibodies in Vertebrate Wildlife, United States, 2009-2014
}

\section{Kasen K. Riemersma ${ }^{1}$ and Nicholas Komar}

Since its discovery in 2009, the tickborne Heartland virus (HRTV) has caused human illness in Missouri, Oklahoma, and Tennessee USA. To better assess the geographic distribution of HRTV, we used wildlife serology as an indicator. This retrospective evaluation determined that HRTV is widespread within the central and eastern United States.

$\mathrm{H}$ eartland virus (HRTV; family Bunyaviridae, genus Phlebovirus) is an emerging public health threat in the United States. HRTV disease, characterized by severe fever, leukopenia, and thrombocytopenia, was first reported in 2 farmers in northwestern Missouri in 2009 (1). Seven additional HRTV disease cases ( 2 fatal) have been reported in Missouri, Tennessee, and Oklahoma (2,3). A study of ticks and mosquitoes in northwestern Missouri detected HRTV infections only in Amblyomma americanum (lone star tick) and thus implicated this tick as a vector (4). The virus was isolated solely from deplete host-seeking nymphs, which presumably were infected as larvae after feeding on a viremic vertebrate host. Because HRTV has yet to be isolated from any wild or domestic animals, the question of vertebrate reservoir(s) remains unanswered. However, high prevalence of seropositive white-tailed deer (Odocoileus virginianus) and raccoon (Procyon lotor) from northwestern Missouri indicate these species as targets for wildlife serosurveillance (5).

The HRTV disease case reports in Tennessee and Oklahoma after the initial case reports in Missouri create the perception that HRTV transmission activity might be dispersing from an origin in northwestern Missouri. However, the geographic range of HRTV activity is unknown. HRTV distribution may mirror the range of the lone star tick, which is distributed throughout most of the central and eastern United States and recently has expanded northward (6). To investigate the hypothesis that HRTV activity occurs throughout the range of its putative tick vector, we conducted a retrospective serosurvey of mainly white-tailed deer and raccoon from 19 states within the heart and periphery of the lone star tick range to look for evidence of HRTV activity.

\section{The Study}

Banked blood samples collected from white-tailed deer, raccoon, and (occasionally) moose (Alces alces) and coyote

Author affiliation: Centers for Disease Control and Prevention,

Fort Collins, Colorado, USA

DOI: http://dx.doi.org/10.3201/eid2110.150380
(Canis latrans) during 2009-2014 were analyzed by plaque-reduction neutralization test for HRTV neutralizing antibodies by using African green monkey kidney (Vero) cell culture. Only samples from healthy live-trapped animals or deceased animals from anthropogenic causes (i.e., hunting, culls, and automobile strikes) were tested. Inclusion of 19 states was opportunistic based on sample availability. We used the plaque-reduction neutralization test to evaluate HRTV seropositivity for white-tailed deer ( $\mathrm{n}$ $=396)$, raccoon $(\mathrm{n}=949)$, coyote $(\mathrm{n}=61)$, and moose $(\mathrm{n}=$ 22) (Table 1). Samples consisted of whole blood dried onto Nobuto strips (Advantec MFS, Inc., Dublin, CA, USA), bloody body cavity fluids, or hemolyzed whole blood. Nobuto strip samples were eluted to 1:10 serum dilution in phosphate buffer solution in accordance with the manufacturer's instructions. All samples were heat-inactivated at $56^{\circ} \mathrm{C}$ for $45 \mathrm{~min}$.

We screened the inactivated samples at 1:20 dilution by mixing serum diluted 1:10 with equal volume of titrated HRTV to approximate a challenge dose of 50 PFUs. Treated Vero cells were incubated for $1 \mathrm{~h}$ at $37^{\circ} \mathrm{C}, 5 \% \mathrm{CO}_{2}$, before applying a nutrient-rich $0.5 \%$ agarose overlay. A second overlay containing Neutral Red was applied after 5-7 d of incubation. Viral plaques were counted 6-12 d after inoculation. A neutralization threshold of $70 \%$ relative to HRTV-only controls was used to determine positive samples. All screen-positive samples were repeat-tested to confirm results. Samples were considered seropositive if they were confirmed as positive at a dilution of $\geq 1: 40$. Comparative neutralization tests with related viruses were not performed, because we had previously found that murine antiserum developed against the other known phleboviruses in the United States - Sunday Canyon virus (7), Rio Grande virus (8), and Lone Star virus (9) - had no appreciable neutralizing activity against HRTV (Table 2). Human antiserum developed against HRTV exhibited weak 1-way neutralization of Lone Star virus and Sunday Canyon virus (Table 2).

Of 1,428 animals, 103 were seropositive: 55 deer, 33 raccoon, 11 coyotes, and 4 moose. Thirteen states had seropositive animals: Florida, Georgia, Illinois, Indiana, Kansas, Kentucky, Maine, Missouri, New Hampshire, North Carolina, Tennessee, Texas, and Vermont (Table 1; Figure 1). Within the 13 states, 20 geographic clusters of seropositive animals were mapped by plotting positive animals by the county where they were collected (Figure 2).

${ }^{1}$ Current affiliation: University of California, Davis, California, USA. 
Table 1. Animals screened and confirmed seropositive for Heartland virus neutralizing antibodies, central and eastern United States, 2009-2014

\begin{tabular}{|c|c|c|c|c|}
\hline State & No. $(\%)$ counties sampled & Species & No. screened & $\begin{array}{c}\text { Confirmed seropositive, no. } \\
(\% ; 95 \% \mathrm{Cl})\end{array}$ \\
\hline Alabama & $5(7)$ & Raccoon (Procyon lotor) & 99 & $0(0 ; 0-4)$ \\
\hline \multirow[t]{2}{*}{ Florida } & $34(51)$ & $\begin{array}{c}\text { White-tailed deer (Odocoileus } \\
\text { virginianus) }\end{array}$ & 65 & $4(6 ; 2-15)$ \\
\hline & & Raccoon & 40 & $0(0 ; 0-9)$ \\
\hline Georgia & $1(1)$ & White-tailed deer & 104 & $15(14 ; 8-23)$ \\
\hline Illinois & $8(8)$ & $\begin{array}{c}\text { Coyote (Canis latrans) } \\
\text { Raccoon }\end{array}$ & $\begin{array}{l}25 \\
68\end{array}$ & $\begin{array}{l}1(4 ; 1-20) \\
0(0 ; 0-5)\end{array}$ \\
\hline Indiana & $13(14)$ & Raccoon & 64 & $2(3 ; 1-11)$ \\
\hline \multirow[t]{2}{*}{ lowa } & $6(6)^{\prime}$ & Coyote & 2 & $0(0 ; 0-5)$ \\
\hline & & Raccoon & 98 & $0(0 ; 0-13)$ \\
\hline Kansas & $10(10)$ & Coyote & 22 & $10(46 ; 27-65)$ \\
\hline Kentucky & $7(6)$ & Raccoon & 44 & $4(9 ; 4-21)$ \\
\hline Maine & $6(38)$ & White-tailed deer & 63 & $7(11 ; 6-21)$ \\
\hline \multirow[t]{3}{*}{ Missouri } & $10(9)$ & Coyote & 12 & $0(0 ; 0-24)$ \\
\hline & & White-tailed deer & 2 & $0(0 ; 0-66)$ \\
\hline & & Raccoon & 75 & $10(13 ; 7-23)$ \\
\hline \multirow[t]{2}{*}{ New Hampshire } & $7(70)$ & Moose (Alces alces) & 22 & $4(18 ; 5-40)$ \\
\hline & & White-tailed deer & 58 & $9(16 ; 7-27)$ \\
\hline North Carolina & $2(2)$ & White-tailed deer & 32 & $13(41 ; 24-59)$ \\
\hline Ohio & $7(8)$ & Raccoon & 94 & $0(0 ; 0-4)$ \\
\hline Pennsylvania & $15(22)$ & Raccoon & 81 & $0(0 ; 0-5)$ \\
\hline Tennessee & $7(7)^{\prime}$ & Raccoon & 92 & $13(14 ; 8-23)$ \\
\hline Texas & $22(9)$ & Raccoon & 85 & $4(5 ; 2-12)$ \\
\hline Vermont & $5(36)$ & White-tailed deer & 72 & $7(10 ; 5-19)$ \\
\hline Virginia & $2(2)$ & Raccoon & 37 & $0(0 ; 0-9)$ \\
\hline West Virginia & $19(35)$ & Raccoon & 72 & $0(0 ; 0-5)$ \\
\hline Total & & & 1,428 & $103(7 ; 6-9)$ \\
\hline
\end{tabular}

\section{Conclusions}

We provide evidence of widespread HRTV transmission activity across the central and eastern United States. Of 13 affected states, only Missouri and Tennessee had previous evidence of HRTV activity. A more stringent neutralization threshold of $80 \%$ would reclassify 14 positive samples to "equivocal," but the number of positive states would remain unchanged. These findings should encourage clinicians and public health officials to consider HRTV as a potential source of illness throughout the eastern United States.

Surprisingly, seropositive white-tailed deer were detected in northern New England, where established populations of lone star ticks are unknown (6). Possible explanations include unreported lone star tick populations, immigration of seropositive deer, alternative tick vectors for HRTV, or presence of a serologically cross-reactive virus. Movement of deer across state boundaries is an unlikely explanation. Extensive lone star tick populations are not reported in neighboring states ( 6 ), and migration of deer from lone star tick-infested regions is unlikely (10). Savage et al. did not detect HRTV RNA in Dermacentor variabilis, the American dog tick (4), but additional tick species inhabit northern New England. Several tick species are reported to transmit severe fever with thrombocytopenia syndrome virus, a closely related phlebovirus found in eastern Asia (11). Further investigation of tick populations and their vector competence for HRTV is warranted, and production of HRTV neutralizing antibodies in response to a serologically similar virus should be investigated. Two new phleboviruses recently detected in Ixodes ticks in the northeastern United States are genetically unrelated to HRTV but raise the possibility that additional undiscovered phleboviruses exist (12). Severe fever with thrombocytopenia syndrome virus-reactive antibodies in wildlife were reported in Minnesota, also peripheral to the lone star tick geographic range, indicating the likely presence of HRTV or a similar virus there (13).

The finding of seropositive moose and coyotes indicates that these mammals are exposed to HRTV in certain situations and might be useful targets for serosurveillance, in addition to deer and raccoon. The full vertebrate host range and the reservoir competence of these mammals for HRTV remains unknown.

The chronology of dispersal of HRTV is unclear. Suggesting that HRTV emerged in northwestern Missouri and

Table 2. Lack of detectable cross-neutralization of HRTV by mouse hyperimmune ascites fluids containing high-titered antibodies to LSV, SCV, and RGV*

\begin{tabular}{lcccc}
\hline Virus (challenge & \multicolumn{4}{c}{ PRNT $_{70}$ antibody titers } \\
\cline { 2 - 5 } dose, PFU) & HRTV & LSV & SCV & RGV \\
\hline HRTV (54) & 160 & $<20$ & $<20$ & $<20$ \\
LSV (214) & 20 & $\geq 640$ & $<20$ & $<20$ \\
SCV (220) & 20 & $<20$ & 320 & $<20$ \\
RGV (14) & $<20$ & $<20$ & $<20$ & 320 \\
\hline *HRTV, Heartland virus; LSV, lone star virus; PRNT $0,70 \%$ plaque- \\
reduction neutralization test; RGV, Rio Grande virus; SCV, Sunday \\
Canyon virus.
\end{tabular}




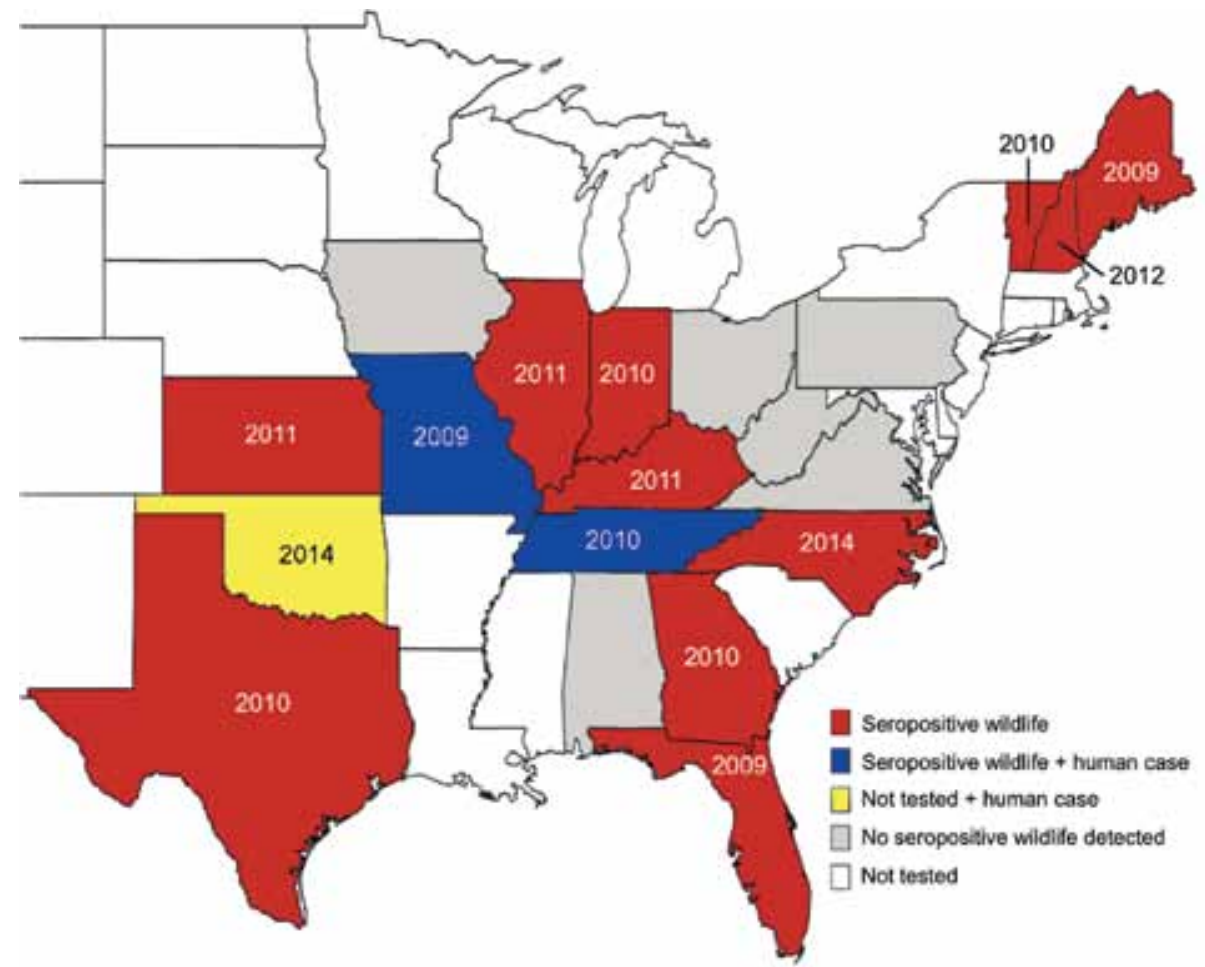

Figure 1. State-level distribution of Heartland virus case reports in humans and seropositive wildlife, central and eastern United States, 2009-2014. Year labels indicate the earliest year of detected HRTV activity. Earliest detection was determined by human case reports in Missouri (1 case) and Oklahoma ( 3 cases) and wildlife serologic data in all other states.

spread to neighboring states to the east and south is overly simplistic. Because animals were sampled at different points of time and space during this study, our data lack robustness to enable comparison of populations over time or between geographic locations. Thus, we are unable to evaluate the dynamics of HRTV spread. Furthermore, the proportions

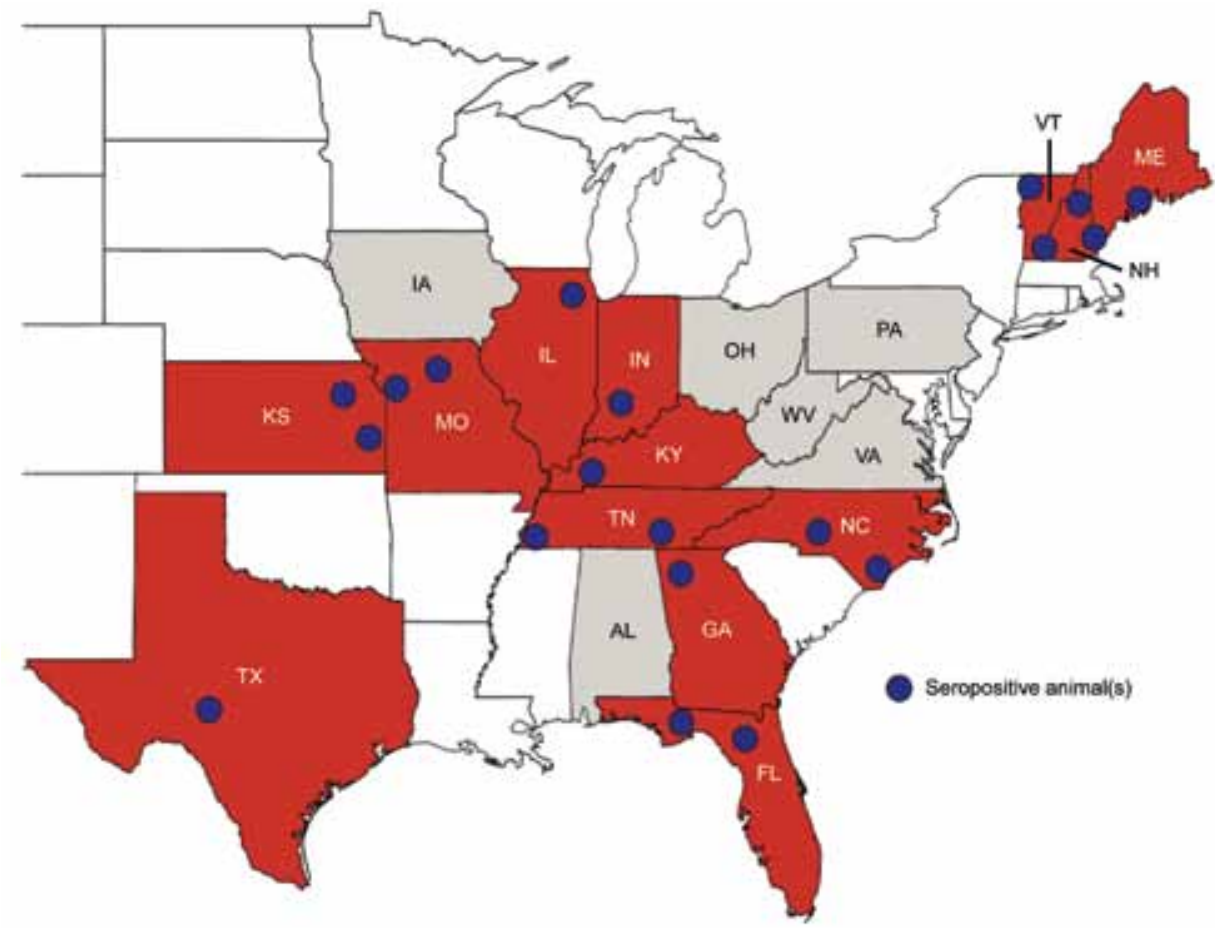

of HRTV-seropositive animal populations lack quantitative value because of our retrospective convenience sampling. Our results simply indicate that HRTV or a very similar virus has circulated in the sampled regions in the recent past and that this activity began as early as 2009. Adult seropositive white-tailed deer were detected in Maine and Florida in
Figure 2. Geographic groupings of confirmed seropositive animals for Heartland virus neutralizing antibodies, central and eastern United States, 2009-2014. Twenty groups were identified in 13 states. The geographic locations of the groups were subjectively approximated by the counties where seropositive animals were collected (blue circles). Red indicates states with seropositive animals; gray indicates states in which no seropositive animals were detected. Because of the sampling design, the data are qualitative. 
2009, and based on the estimated ages of affected deer (data not shown), the infections could have occurred as early as 2003. A much larger retrospective serosurvey is necessary to elucidate HRTV's history of emergence.

\section{Acknowledgments}

We thank our colleagues who provided blood and serum samples: John Baroch, Dennis Kohler (US Department of Agriculture National Wildlife Research Center); Maria Palamar (North Carolina Wildlife Resources Commission); Mark Cunningham (Florida Fish and Wildlife Conservation Commission); William Nicholson and John-Paul Mutebi (Centers for Disease Control and Prevention [CDC] Division of Vector-Borne Diseases). We thank Brad Biggerstaff for his advice on biostatistics.

This study was supported by the CDC Epidemiology Elective Program and funded by CDC.

Dr. Riemersma was a veterinary student in the CDC Epidemiology Elective program at the Division of Vector-Borne Diseases during this study and is currently a PhD student at the University of California, Davis. His research interests include the genetics and ecology of pathogen emergence, with particular interest in vector-borne viruses.

Dr. Komar is the vertebrate ecologist for the Arbovirus Diseases Branch, Division of Vector-Borne Diseases, National Center for Emerging and Zoonotic Infectious Diseases, CDC, Fort Collins, Colorado. His major research interest is the role of vertebrate hosts in arbovirus transmission cycles.

\section{References}

1. McMullan LK, Folk SM, Kelly AJ, MacNeil A, Goldsmith CS, Metcalfe MG, et al. A new phlebovirus associated with severe febrile illness in Missouri. N Engl J Med. 2012;367:834-41. http://dx.doi.org/10.1056/NEJMoa1203378

2. Pastula DM, Turabelidze G, Yates KF, Jones TF, Lambert AJ, Panella AJ, et al. Notes from the field: Heartland virus diseaseUnited States, 2012-2013. MMWR Morb Mortal Wkly Rep. 2014;63:270-1.

3. Oklahoma State Department of Health. Oklahoma State Health Department confirms first case and death of Heartland virus [cited 2014 Jul 2]. http://www.ok.gov/health/Organization/ Office_of_Communications/News_Releases/2014_News_Releases/
Oklahoma_State_Health_Department_Confirms_First_Case_and Death_of_Heartland_Virus.html

4. Savage HM, Godsey MS, Lambert A, Panella NA, Burkhalter KL, Harmon JR, et al. First detection of Heartland virus (Bunyaviridae: Phlebovirus) from field-collected arthropods. Am J Trop Med Hyg. 2013;89:445-52. http://dx.doi.org/10.4269/ajtmh.13-0209

5. Bosco-Lauth AM, Panella NA, Root JJ, Gidlewski T, Lash RR, Harmon JR, et al. Serological investigations of Heartland virus (Bunyaviridae: Phlebovirus) exposure in wild and domestic animals adjacent to human case sites in Missouri 2012-2013. Am J Trop Med Hyg. 2015;92:1163-7. http://dx.doi.org/10.4269/ ajtmh.14-0702

6. Springer YP, Eisen L, Beati L, James AM, Eisen RJ. Spatial distribution of counties in the continental United States with records of occurrence of Amblyomma americanum (Ixodida: Ixodidae). J Med Entomol. 2014;51:342-51. http://dx.doi.org/ 10.1603/ME13115

7. Yunker CE, Clifford CM, Thomas LA, Keirans JE, Casals J, George JE, et al. Sunday Canyon virus, a new ungrouped agent from the tick Argas (A.) cooleyi in Texas. Acta Virol. 1977; 21:36-44.

8. Calisher CH, McLean RG, Smith GC, Szmyd DM, Muth DJ, Lazuick JS. Rio Grande-a new phlebotomus fever group virus from south Texas. Am J Trop Med Hyg. 1977;26:997-1002.

9. Swei A, Russell BJ, Naccache SN, Kabre B, Veeraraghavan N, Pilgard MA, et al. The genome sequence of lone star virus, a highly divergent bunyavirus found in the Amblyomma americanum tick. PLoS ONE. 2013;8:e62083. http://dx.doi.org/ 10.1371/journal.pone.0062083

10. Lesage L, Crête M, Huot J, Dumont A, Ouellet J-P. Seasonal home range size and philopatry in two northern white-tailed deer populations. Can J Zool. 2000;78:1930-40. http://dx.doi.org/ 10.1139/z00-117

11. Yun S-M, Lee W-G, Ryou J, Yang S-C, Park S-W, Roh JY, et al. Severe fever with thrombocytopenia syndrome virus in ticks collected from humans, South Korea, 2013. Emerg Infect Dis. 2014;20:1358-61.

12. Tokarz R, Williams SH, Sameroff S, Sanchez Leon M, Jain K, Lipkin WI. Virome analysis of Amblyomma americanum,

Dermacentor variabilis, and Ixodes scapularis ticks reveals novel highly divergent vertebrate and invertebrate viruses. J Virol. 2014;88:11480-92. http://dx.doi.org/10.1128/JVI.01858-14

13. Xing Z, Schefers J, Schwabenlander M, Jiao Y, Liang M, Qi X, et al. Novel bunyavirus in domestic and captive farmed animals, Minnesota, USA. Emerg Infect Dis. 2013;19:1487-9. http://dx.doi.org/10.3201/eid1908.130165

Address for correspondence: Nicholas Komar, Centers for Disease Control and Prevention, 3156 Rampart Rd, Fort Collins, CO 80521, USA; email: nkomar@cdc.gov

\section{Like our podcasts?}

Sign up to receive email announcements
when a new podcast is available. www.cdc.gov/eid/subscribe.htm

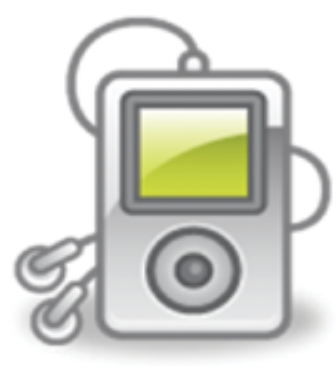

